\title{
Role of Physiotherapist in Critical Care Situations: Recent Perspective
}

\author{
Jyoti $^{1}$ Meenu ${ }^{2}$ \\ ${ }^{1}$ Department of Clinical Physiotherapy, ISIC, New Delhi, India \\ ${ }^{2}$ Department of Sport Medicine and Sciences, MYAS-GNDU, \\ Amritsar, Punjab, India \\ J Card Crit Care TSS 2018;2:14-18
}

\begin{abstract}
Address for correspondence Jyoti, MPT(M), Department of Clinical Physiotherapy, ISIC, Vasant Kunj, New Delhi, India

(e-mail: theexpertphysio@gmail.com).
\end{abstract}

\begin{abstract}
Keywords

- breathing exercises

- early mobilization

- ICU

- physiotherapy

Physiotherapy is part of a multidisciplinary team and plays an important role in the critical care unit to improve patients' quality of life. It is reported that a patient mechanically ventilated for more than a week shows muscular weakness approximately $25 \%$ and approximately $90 \%$ of patients have ongoing muscular weakness and poor quality of life. Physiotherapy in critical care units and high dependency units play a vital role to promote lung functions and early discharge. There are more ventilator-free days for patient with early physiotherapy in intensive care unit (ICU) compared with standard care. A large number of physical limitations are faced by patient and professionals in ICU and respiratory intermediate intensive care units. Declined pulmonary function, persistent muscle weakness, prolonged mechanical ventilation, and contracture are associated with poor quality of life and long-time staying in hospitals. Physiotherapy is a main component of patient management in critical care units and involves mobilization activities, functional positioning, passive- and active-assisted movements of extremities, sitting, bedside standing, walking with support, early mobilization, postural drainage, clear airway secretions, manual hyperinflation, percussion and vibration, assisted and resisted exercise, and electric stimulation.
\end{abstract}

\section{Introduction}

Physiotherapist is an important member of multidisciplinary team and plays an important role in critical care unit in improving the patient's quality of life. ${ }^{1,2}$ It is reported that approximately $25 \%$ patients who have been mechanically ventilated for more than a week show muscular weakness, and approximately 50 to $90 \%$ of patients who had long-term stay in intensive care unit (ICU) had ongoing muscular weakness, poor quality of life, and functional decline with increased morbidity. ${ }^{3}$ Physiotherapy expertise works for assessment and management of several musculoskeletal and physical complications in ICU. ${ }^{4}$ Physiotherapy in respiratory conditions brings short-term as well as medium-term benefits for respiratory illness and patients needing extracorporeal membrane oxygenation (ECMO).

Physiotherapy treatment, such as positioning, percussion, postural drainage and suctioning, vibration, berating exercises, and mobilization (-Fig. 1), in critical care units and high-dependency units plays a vital role in promoting lung functions and early discharge from hospital and ICUs. ${ }^{5-8}$

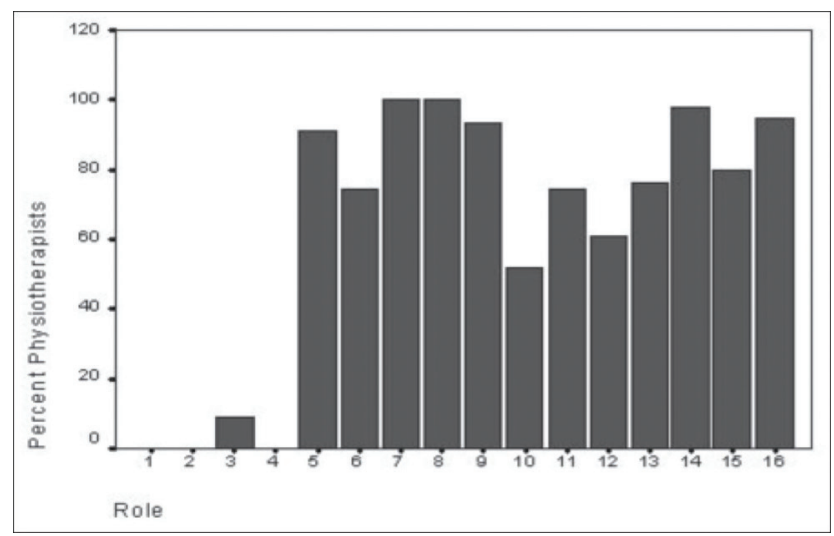

Fig. 1 Physiotherapy and physiotherapist role in intensive care units of India in different physical therapies.
DOI https://doi.org/ 10.1055/s-0038-1673494. ISSN 2457-0206.
Copyright @2018 Official Publication of The Simulation Society (TSS), accredited by International Society of Cardiovascular Ultrasound (ISCU).
License terms

() (1) $\ominus \circledast$ 
1-Percussion only, 2-vibration only, 3-percussion + vibration, 4-suctioning only, 5-chest manipulation (percussion + vibration + suctioning), 6-positioning, 7-mobilization, 8-breathing exercises, 9-incentive spirometry, 10-ambulation of tracheostomy patients in ICU, 11-ambulation of non-intubated patients in ICU, 12-counseling 13-nebulization + humidify cation, 14-postural drainage, 15-forced expiratory technique, and 16-assisted coughing and huffing.?

It helps in decreasing the risk of ventilator-associated pneumonia and respiratory muscle weakness, improving lung volumes and capacities, and influencing or preventing physical impairments, ${ }^{9-16}$ within the International Classification of Functioning (ICF) domains, regarding diagnostics and effective and safe physiotherapy treatment strategies aiming at early mobilization and physical activity for patients in an ICU. ${ }^{17-19}$

\section{Physiotherapy Rehabilitation}

During critical illness to prevent and mitigate adverse effect of prolonged immobilization in ICU, physiotherapy plays an integral part. Physiotherapists deliver active or passive services and focus on early mobilization, which is beneficial for reducing the long staying time in ICU and add to quality of life. Lack of early progressive physiotherapy results in increased costs of health provision services, extensive period of rehabilitation, and long-term follow-up with residual disabilities. According to the National Institute of Health and Clinical excellence (NICE), European Respiratory Society, and ICU medicine, there are more ventilator-free days for patients with early physiotherapy in ICU compared with standard care.

\section{Problems and Physical Limitations in Intensive Care Unit Patients}

A large number of physical limitations are faced in the ICU and respiratory intermediate ICUs (RIICUs) by patients and professionals. Declining pulmonary function, persisting muscle weakness, prolonged mechanical ventilation, and contracture are associated with poor quality of life and long-time staying in hospitals. ${ }^{20}$ Lack or inadequate level of appropriate therapy is associated with deconditioning, recurrent symptoms, and muscle wasting. Almost half of the ICU patients with multiple organ failure or condition requiring prolonged mechanical ventilation show chronic critical illness, prolonged bed rest, and incontinence prevelences. ${ }^{20,21}$

\section{Physiotherapy Recommendations}

Scientific society has recommended physiotherapy as a main component of patient management in critical care units or patient with critical illness. Traditional physiotherapy strategies involve mobilization activities in progressive manner such as positioning or decubitus change, functional positioning, passive and active assisted movements of extremities, sitting, bedside standing, and walking with support. Now there is a paradigm shifting toward early physiotherapy or aimed to improve patients' quality of life and decrease ICU-related complications such as respiratory distress or prolonged stay in patients with ECMO. Starting of early mobilization not more than 1 and 2 days after is beneficial to prevent ICU-related complications. Along with mobilization, strengthening of respiratory muscle improves respiratory functional outcomes and stability of the patient. Every patient should be screened for the red flags or contraindications for risks and benefits before and during every physiotherapy treatment session. To improve range of motion for joint contractures and muscle tone in unconscious patients, passive joint movements should be monitored daily. ${ }^{22-24}$ In patients who already have joint contractures, stretching, splinting, or passive movements with continuous passive motion (CPM) should be applied for 20 minutes daily. ${ }^{21,25}$

A new paradigm in physiotherapy involves early mobilization, postural drainage, clear airway secretions, manual hyperinflation, percussion and vibration, and assisted and resisted exercises.

\section{Early Mobilization Physiotherapy Role}

Due to inactivity, inflammation in patients in ICU presents with muscular weakness. Pain treatment and management devices such as endotracheal tube, catheters, and thoracotomy tubes further contribute to muscular weakness or disuse atrophy. It involves changing position hourly or frequently in conscious or unconscious patients. Only shortterm effects are available for positioning. Evidences are available for selecting appropriate treatment and suitable patient for mobilization. Early mobilization is helpful in sitting, standing, and walking with assistive aids (-Fig. 2). Sitting, standing, and walking with aids increases gaseous exchange while prolonged bedrest increases the risk of deep vein thrombosis, improve chest wall strength, gaseous exchange and functional residual capacities. ${ }^{26-28}$

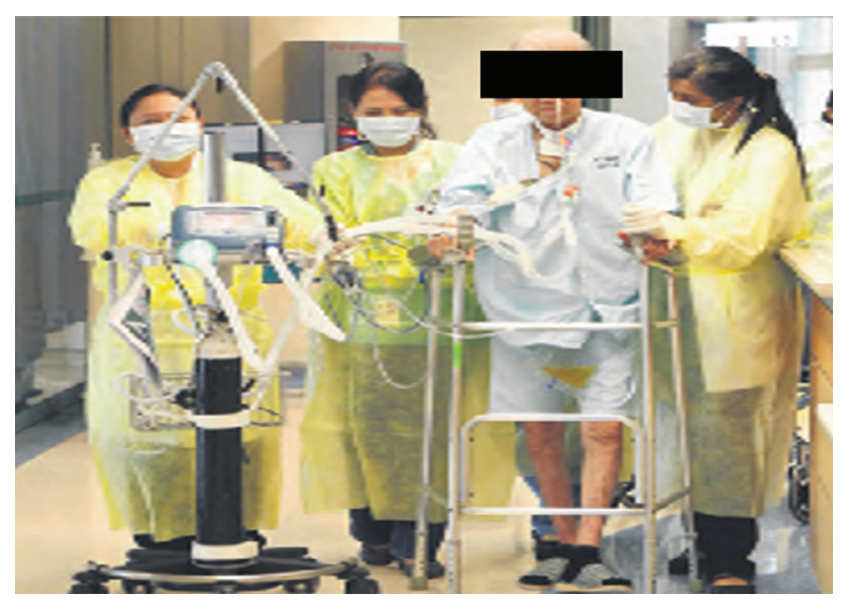

Fig. 2 Mobilization (standing and walking) with walking aid in intensive care unit. 

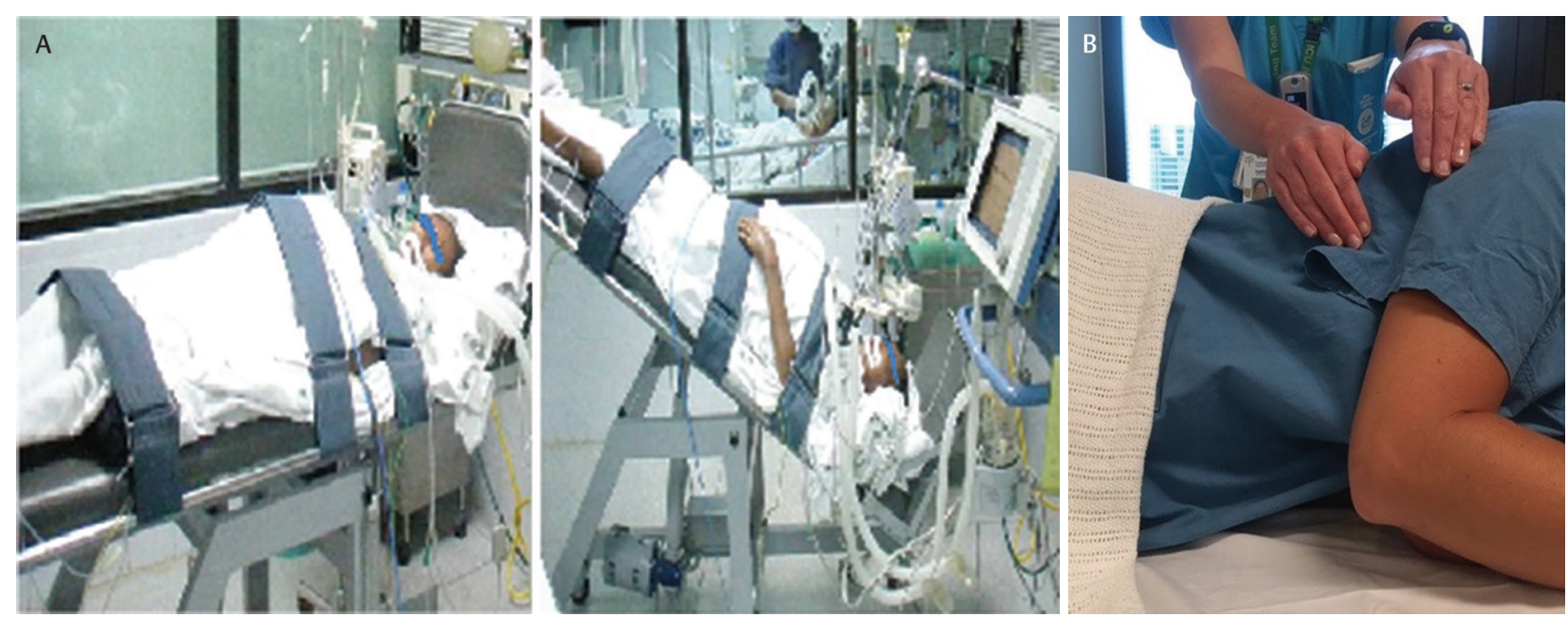

Fig. 3 (A) Position of patient for postural drainage. (B) Percussion in side lying.

\section{Postural Drainage}

This technique is beneficial to drain out secretions with the help of gravity effect. Patient is positioned in different positions ( - Fig. $\mathbf{3 A}$ ) according to lung lobes from which secretion needs to be drained out with the help of pillows or adjustable beds in ICU. It includes different techniques such as percussion (-Fig. 3B), shaking, or vibration coughing to move secretions toward upper airway. The collected secretion is suctioned out from the upper airway.

Positioning of patient with 30\% head elevation decreases the risk of aspiration and ventilator-associated pneumonia. Chest physiotherapy helps in improving gas exchange and mucus clearance.

In a randomized control study, the authors concluded that the patients who were mechanically ventilated in ICU resulted with improved lung collapse and prevented ventilator-associated pneumonia after chest physiotherapy and postural drainage. ${ }^{29-32}$

\section{Manual Hyperinflation}

The patient with mechanical ventilation airway secretions is moved out to large respiratory tract with the help of manual hyperinflation with inflation bag ( - Fig. 4) and amount of secretions accumulated in large respiratory tract are suctioned out. It can improve the oxygenation and lung compliances.This is a very effective technique to use in ICU patients. ${ }^{33-36}$ Self-inflating bag is used to deliver a $50 \%$ greater volume of gas than tidal volume via an endotracheal or tracheostomy tube which have potential advantages in different conditions such as reversal of acute lobar atelectasis, alveolar recruitment via channels of collateral ventilation, improvement in $\mathrm{PaO}_{2}$, and improved static lung compliance.

\section{Electric Stimulation (TENS)}

This is used in conscious patient for extremity pain management. Small trials recorded benefits for muscular strengthening and muscle mass. ${ }^{37}$

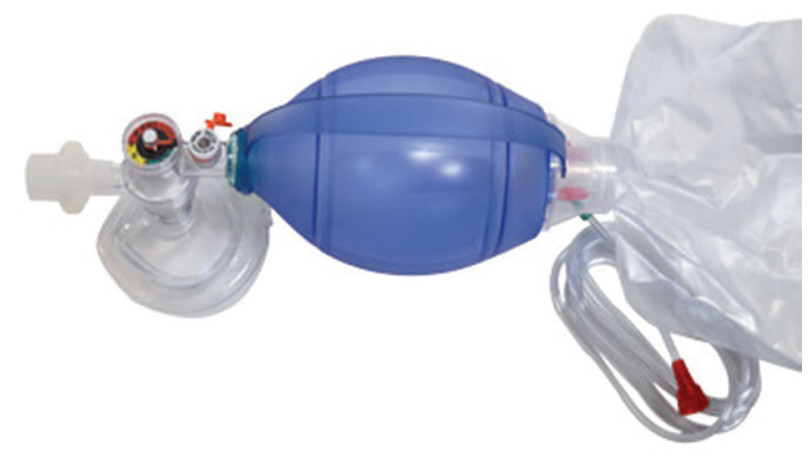

Fig. 4 Ambu bag used for manual hyperinflation in intensive care unit.

\section{Breathing Exercises}

Early addition of breathing exercises such as forced expiration (-Fig. 5), deep breathing, and incentive spirometry techniques (-Fig. 6) include increasing chest expansion and involve voluntary increase in lung volumes greater than lung capacity. It will also help to clear the airway secretions via strengthening the respiratory muscles which undergo weakness during rest period and result in failure forceful coughing. ${ }^{5,6,38}$

\section{Role of Physiotherapist in ICU}

In ICU, physiotherapists are involved in the prevention and treatment of pulmonary, circulatory, and musculoskeletal system and integumentary complications, by regular chest physiotherapy, graded mobilization, and proper positioning of patients. The role of physiotherapists as stated by Kathy Stiller in the ICU are positioning, mobilization, manual hyperinflation, percussion, vibration, coughing, suctioning, various breathing exercises, and limb exercises. Colin F. Mackenzie stated the role of physiotherapists in ICU as positioning, postural drainage, percussion, vibration, manual lung inflation, coughing, tracheal suctioning, breathing exercises, patient mobilization and application of aerosol, 


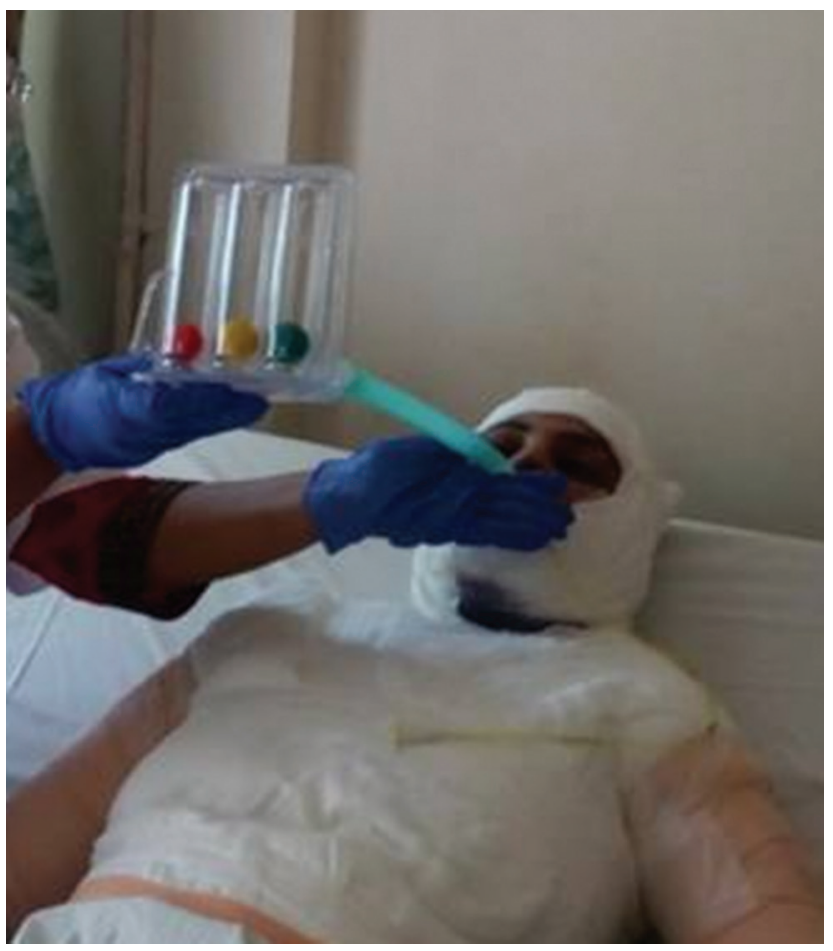

Fig. 5 Spirometry breathing exercises.

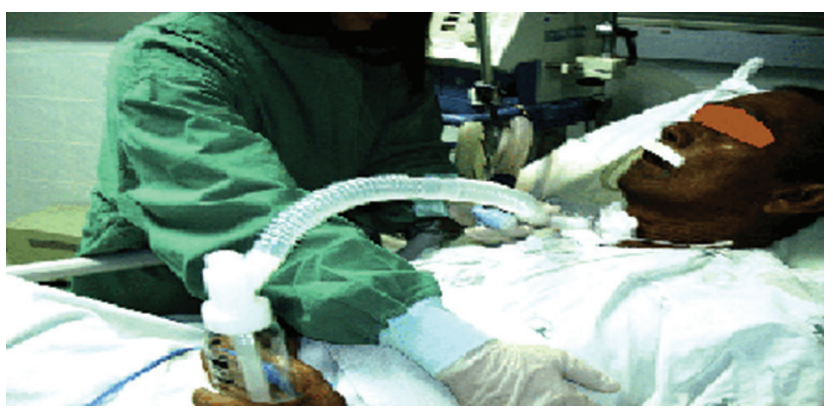

Fig. 6 Forced expiration breathing exercise for lower lobe.

humidification, incentive spirometry, forced expiratory techniques, bronchodilators, and mucolytic agents.

Indian ICU physiotherapists perform the roles of both chest physiotherapy and mobilization. Apart from the roles mentioned in a telephonic interview, therapists are also involved in application of noninvasive ventilation, proprioceptive neuromuscular facilitation in respiration, bedsore management, active cycle of breathing techniques, and autogenic drainage. Therapists in ICU are not only involved in chest physiotherapy techniques, but also are reported to have a very active role in mobilization and positioning. ${ }^{39}$

\section{Conclusion}

Early implementation of physiotherapy treatment in ICU patient plays a significant role to prevent the mechanical ventilator complications, decreased muscle strength, and respiratory complications. With the help of new physiotherapy paradigm, there is improvement in quality of life of patients and also decrease in the cost of hospital stay.

\section{Conflict of Interest}

None.

\section{References}

1 Berney S, Haines K, Denehy L. Physiotherapy in critical care in Australia. Cardiopulm Phys Ther J 2012;23(1):19-25

2 Jones AY, Hutchinson RC, Oh TE. Chest physiotherapy practice in intensive care units in Australia, the UK and Hong Kong. Physiother Theory Pract 1992;8:39-47

3 Stevens RD, Dowdy DW, Michaels RK, Mendez-Tellez PA, Pronovost PJ, Needham DM. Neuromuscular dysfunction acquired in critical illness: a systematic review. Intensive Care Med 2007;33(11):1876-1891

4 Hermans G, De Jonghe B, Bruyninckx F, Van den Berghe G. Interventions for preventing critical illness polyneuropathy and critical illness myopathy. Cochrane Database Syst Rev 2014;1(1):CD006832

5 Stiller K. Physiotherapy in intensive care: towards an evidence-based practice. Chest 2000;118(6):1801-1813

6 Mackenzie CF, Ciesla N, Imle PC. Chest Physiotherapy in Intensive Care Unit. 2nd ed. Baltimore, MD: Williams and Wilkins; 1989: 93-187

7 Kumar JA, Maiya AG, Pereira D. Role of physiotherapists in intensive care units of India: a multicenter survey. JCCM 2007; 11(4):198-203

8 Jham K. Role of physiotherapy in critical ill evidence-based practice. J Crit Care 2009;24(3):e17-e18

9 Bourdin G, Barbier J, Burle JF, et al. The feasibility of early physical activity in intensive care unit patients: a prospective observational one-center study. Respir Care 2010;55(4):400-407

10 Gerovasili V, Stefanidis K, Vitzilaios K, et al. Electrical muscle stimulation preserves the muscle mass of critically ill patients: a randomized study. Crit Care 2009;13(5):R161

11 Schweickert WD, Kress JP. Implementing early mobilization interventions in mechanically ventilated patients in the ICU. Chest 2011;140(6):1612-1617

12 Needham DM. Mobilizing patients in the intensive care unit: improving neuromuscular weakness and physical function. JAMA 2008;300(14):1685-1690

13 Parker A, Sricharoenchai T, Needham DM. Early rehabilitation in the intensive care unit: Preventing impairment of physical and mental health. Curr Phys Med Rehabil Rep 2013;1(4):307-314

14 Burtin C, Clerckx B, Robbeets C, et al. Early exercise in critically ill patients enhances short-term functional recovery. Crit Care Med 2009;37(9):2499-2505

15 Kayambu G, Boots R, Paratz J. Physical therapy for the critically ill in the ICU: a systematic review and meta-analysis. Crit Care Med 2013;41(6):1543-1554

16 Calvo-Ayala E, Khan BA, Farber MO, Ely EW, Boustani MA Interventions to improve the physical function of ICU survivors: a systematic review. Chest 2013;144(5):1469-1480

17 Atkinson HL, Nixon-Cave K. A tool for clinical reasoning and reflection using the international classification of functioning, disability and health (ICF) framework and patient management model. Phys Ther 2011;91(3):416-430

18 Organization WH.International Classification of Functioning Disability and Health: ICF. Geneva, Switzerland: World Health Organization; 2001

19 Levels of Evidence Working Group.Levels of evidence [Internet]. Oxford Centre for Evidence-Based Medicine. OCEBM 2009. Available at: https://www.cebm.net/2009/06/ oxford-centre-evidence-based-medicine-levels-evidencemarch-2009/. Accessed July 4, 2018 
20 Ambrosino N, Venturelli E, Vagheggini G, Clini E. Rehabilitation, weaning and physical therapy strategies in chronic critically ill patients. Eur Respir J 2012;39(2):487-492

21 Gosselink R, Bott J, Johnson M, et al. Physiotherapy for adult patients with critical illness: recommendations of the European Respiratory Society and European Society of Intensive Care Medicine Task Force on Physiotherapy for Critically Ill Patients. Intensive Care Med 2008;34(7):1188-1199

22 Hanekom S, Gosselink R, Dean E, et al. The development of a clinical management algorithm for early physical activity and mobilization of critically ill patients: synthesis of evidence and expert opinion and its translation into practice. Clin Rehabil 2011;25(9):771-787

23 Clavet H, Hébert PC, Fergusson DA, Doucette S, Trudel G. Joint contractures in the intensive care unit: association with resource utilization and ambulatory status at discharge. Disabil Rehabil 2011;33(2):105-112

24 Kasotakis G, Schmidt U, Perry D, et al. The surgical intensive care unit optimal mobility score predicts mortality and length of stay. Crit Care Med 2012;40(4):1122-1128

25 Griffiths RD, Palmer TE, Helliwell T, MacLennan P, MacMillan RR. Effect of passive stretching on the wasting of muscle in the critically ill. Nutrition 1995;11(5):428-432

26 Morris PE, Goad A, Thompson C, et al. Early intensive care unit mobility therapy in the treatment of acute respiratory failure. Crit Care Med 2008;36(8):2238-2243

27 Mendez-Tellez PA, Needham DM. Early physical rehabilitation in the ICU and ventilator liberation. Respir Care 2012;57(10):1663-1669

28 Schweickert WD, Pohlman MC, Pohlman AS, et al. Early physical and occupational therapy in mechanically ventilated, critically ill patients: a randomised controlled trial. Lancet 2009;373(9678):1874-1882

29 Andrews J, Sathe NA, Krishnaswami S, McPheeters ML. Nonpharmacologic airway clearance techniques in hospitalized patients: a systematic review. Respir Care 2013;58(12):2160-2186

30 Chen YC, Wu LF, Mu PF, Lin LH, Chou SS, Shie HG. Using chest vibration nursing intervention to improve expectoration of airway secretions and prevent lung collapse in ventilated ICU patients: a randomized controlled trial. J Chin Med Assoc 2009;72(6):316-322

31 Ntoumenopoulos G, Presneill JJ, McElholum M, Cade JF. Chest physiotherapy for the prevention of ventilator-associated pneumonia. Intensive Care Med 2002;28(7):850-856

32 Lemyze M, Mallat J, Duhamel A, et al. Effects of sitting position and applied positive end-expiratory pressure on respiratory mechanics of critically ill obese patients receiving mechanical ventilation. Crit Care Med 2013;41(11):2592-2599

33 Paulus F, Veelo DP, de Nijs SB, et al. Manual hyperinflation partly prevents reductions of functional residual capacity in cardiac surgical patients--a randomized controlled trial. Crit Care 2011;15(4):R187

34 Paulus F, Binnekade JM, Middelhoek P, Schultz MJ, Vroom MB. Manual hyperinflation of intubated and mechanically ventilated patients in Dutch intensive care units--a survey into current practice and knowledge. Intensive Crit Care Nurs 2009;25(4):199-207

35 Paulus F, Binnekade JM, Vroom MB, Schultz MJ. Benefits and risks of manual hyperinflation in intubated and mechanically ventilated intensive care unit patients: a systematic review. Crit Care 2012;16(4):R145

36 Paulus F, Binnekade JM, Vermeulen M, Vroom MB, Schultz MJ. Manual hyperinflation is associated with a low rate of adverse events when performed by experienced and trained nurses in stable critically ill patients--a prospective observational study. Minerva Anestesiol 2010;76(12):1036-1042

37 Jahangirifard A, Razavi M, Ahmadi ZH, Forozeshfard M. Effect of TENS on postoperative pain and pulmonary function in patients undergoing coronary artery bypass surgery. Pain Manag Nurs 2018;19(4):408-414

38 Denehy L, Berney S. Physiotherapy in the intensive care unit. Phys Ther Rev 2006;11(1):49-56

39 Chaboyer W, Gass E, Foster M. Patterns of chest physiotherapy in Australian Intensive Care Units. J Crit Care 2004;19(3):145-151 